\title{
Toward the Rapid Treatment of Depression by Selective Inhibition of Central Stress Circuits
}

\author{
Eric A. Stone*, Yan Lin and Yasmeen Sarfraz
}

Department of Psychiatry, New York University School of Medicine, 550 First Ave, New York, NY 10016, USA

\begin{abstract}
A long standing problem with antidepressant drugs is their delayed onsets of action which has made them unsatisfactory in the rapid treatment of serious depressions involving agitated and suicidal behavior. Two new approaches to this problem involve the glutamatergic antagonist, ketamine, recently reviewed, and the acute inhibition of central stress circuits, which is the subject of the present review. The rationale behind stress-circuit inhibition comes from the findings that both clinical and experimental depressions are accompanied by increased neural activity in the stress network together with inhibited activity in regions underlying active motivated behaviors, and that both changes are reversed by effective antidepressant treatment. It has been shown further that direct pharmacological inhibition of central noradrenergic stress nuclei produces immediate reversal of depressive-like passive as well as sickness behaviors. Dipivalyl-6-fluoronorepinephrine (dp6FNE), a brain-permeable pro-drug of 6FNE, a full agonist at inhibitory brain $\alpha$ adrenoceptors in brainstem noradrenergic stress nuclei, has been developed and found in preliminary studies to cause rapid reversal of both passivity and anhedonia as well as anxiolysis without significant hypoactivity in the open field. Low doses of agonists of glucocorticoid and 5HT1A autoreceptors, which respectively inhibit the hypothalamic-pituitaryadrenal axis and serotonergic stress systems, may also share these effects as well as potentiate the actions of dp6FNE. Anti-stress effects may also be involved in the rapid therapeutic effects found with intracerebral administration of first generation antidepressants and may prove helpful in potentiating the therapeutic actions of stimulants.
\end{abstract}

Keywords: Antidepressants, delayed onset, depression models, stress, brain networks, motivated behavior, autoreceptors, agonists, targeting, pro-drugs.

\section{INTRODUCTION}

Until recently there have been no reliably effective means for the rapid alleviation of serious depressions that involve highly agitated or suicidal behaviors. Within the past several years, however, two potential methods have been discovered. The first was observed in clinical studies of the glutamatergic antagonist, ketamine, while the second has been suggested by preclinical research on the behavioral effects of inhibition of central stress circuits by agonists of autoreceptors on stress neurons. Each of these methods may eventually prove to have unique advantages and to be suited for different patient populations. As there have been several recent reviews of ketamine treatment [1,2], the present paper will deal with studies of targeted inhibition of stress circuits.

Evidence from basic animal research has accumulated to suggest the existence of two principal CNS networks involved in behavioral depression. The first, the stress network, mediates organismal responses to stress and danger while the second, the "active" network organizes and executes motivated active learned or "voluntary" coping behaviors $[3,4]$. The stress network consists of a distributed group of structures including medullary and pontine noradrenergic and adrenergic nuclei (A1, A2, C1, C2, C3 and locus coeruleus or LC), the hypothalamic paraventricular

*Address correspondence to this author at the Psychiatry MHL HN510, NYU Med Ctr, 550 First Ave, New York, NY 10016, USA; Tel: 212-2635740; Fax: 212-263-0712; E-mail: eric.stone@nyu.edu nucleus $(\mathrm{PVH})$, midbrain serotonergic raphe nuclei and the periaqueductal grey (PAG), subcortical limbic nuclei of the amygdala (AMYG) and bed nucleus of the stria terminalis (BNST), and prelimbic and infralimbic areas of the prefrontal cortex (PFC) (Table 1) [5,6]. This network controls various autonomic, neuroendocrine and instinctive behavioral responses to threatened or actual dangers or deviations from homeostasis. The autonomic and hormonal stress responses are well known and have recently been reviewed $[5,6]$. The instinctive behavioral responses include fear [7], freezing [8], agitation and flight [9], aggression [10] and behavioral passivity $[11,12]$. There is recent speculation that these areas may also trigger the aversive emotional responses of depression in humans including black mood, pessimism, despair, guilt, worthlessness and demoralization, although the evidence for this is still largely indirect [12-14].

The network underlying motivated active behavior, on the other hand, involves most of the remaining non-stress areas of the brain and controls the various sensory, motor, motivational and cognitive processes involved in active coping responses $[15,16]$. These behaviors are generally learned or "voluntary" in humans and can be motivated by either positive or "controlled" negative reinforcement generating approach or escape and avoidance responses, respectively. Some of the more prominent regions include the secondary motor cortex (M2), which generates and organizes sequential motor acts, the piriform cortex (PIR), which processes olfactory information necessary for exploratory and foraging behaviors [17], the orbital cortex 
Table 1. Summary of Central Stress Network

\begin{tabular}{|c|c|c|}
\hline CNS Level & Nucleus/Region & Function \\
\hline \multirow{2}{*}{ Medulla } & $\mathrm{A} 1 / \mathrm{C} 1$ & glucose regulation, behavioral inhibition \\
\hline & $\mathrm{A} 2 / \mathrm{C} 2$ & baro \& chemoreflexes, behavioral inhibition \\
\hline Pons & $\mathrm{LC}$ & arousal, behavioral inhibition, suppress seizure activity \\
\hline \multirow{2}{*}{ Midbrain } & DR & Behavioral inhibition, mood regulation \\
\hline & PAG & fight, flight, freezing, passivity, agitation, panic \\
\hline \multirow{6}{*}{ Hypothalamus } & PVH & HPA, SNS outflow, oxytocin, vasopressin release \\
\hline & MPOA & body temperature regulation, \\
\hline & $\mathrm{DM}$ & autonomic responses \\
\hline & Arcuate & regulation energy expend and feeding \\
\hline & LH & regulation energy expend and feeding, orexin \\
\hline & $\mathrm{SCN}$ & circadian rhythms \\
\hline \multirow{3}{*}{ Subcortical (Limbic) } & Amyg-CeA & phasic fear, freezing ,escape/avoidance, autonomic arousal, excitation of HPA axis \\
\hline & Amyg-MeA \& BLA & avoidance, disinhibits amyg \& pvh by inhibition of gaba interneurons \\
\hline & BNST & prolonged fear and anxiety prolonged, autonomic response \\
\hline \multirow{2}{*}{ Cortical } & IFL & excitation of amyg and HPA \\
\hline & PLC & inhibition of amyg and HPA \\
\hline
\end{tabular}

Shows the chief stress nuclei and brain areas at various levels of the CNS along with known functions (see text for references). Abbreviations: Amyg, amygdala; BLA, basolateral nucleus; CeA, central nucleus; DM, dorsomedial nucleus; HPA, hypothalamic pituitary adrenal axis; IFL, infralimbic cortex; LC, locus coeruleus; LH, lateral hypothalamus; MeA; medial nucleus; MPOA, medial preoptic area; PAG, periaqueductal grey; PLC, prelimbic cortex; PVH, paraventricular nucleus of hypothalamus; SCN, suprachiasmatic nucleus; SNS, sympathetic nervous system.

(ORB), mediating reward evaluation and planning [18-20], the cingulate involved in effort-based decision making $[21,22]$, the mesocortical and mesolimbic dopaminergic systems which underlie reward and effort response-decision making [23], and the lateral septal nucleus (LSEPT), which organizes primarily positively motivated behaviors [24].

In addition several areas of the "active" network, including the hippocampus (HIPPO), prelimbic PFC and (LSEPT) have been shown to inhibit portions of the stress network, including the PVH and AMYG [5], while several of the stress areas have been assumed to cause an analogous inhibition of "active" regions [25-27]. These interactions are assumed to underlie the reciprocal functional activities of the two networks $[3,28]$.

This reciprocity can be seen in the mouse brain from the Fos responses of principal neurons in representative regions of each network (PVH for the stress and PIR for the "active" network) after either a stressor (restraint) or a session of operant responding for water reward (Fig. 1). After $1 \mathrm{hr}$ of restraint stress, the medial parvocellular neurons of the $\mathrm{PVH}$ show intense activation whereas the pyramidal output cells of the PIR cortex show somewhat lesser activity whereas after $40 \mathrm{~min}$ of a rewarding behavioral task, the reverse pattern is observed. This same reciprocity occurs throughout these networks producing high positive correlations among the various structures of each network and high inverse correlations of structures between the two $[25,27,29,30]$. The small activation of the "active" network by acute stress that can be seen above in the PIR with acute restraint stress appears to be associated with initial attempts at escape as it disappears as these are extinguished by prolonged or repeated exposure to an inescapable stressor [25,31].

Depression and its probable evolutionary forerunner, sickness behavior [32], have been found to be accompanied by the stress pattern, i.e., high activity in stress regions with low activity in the "active" areas. This has been observed both in depressed patients [13,14,33] and in animal models of depression and sickness behavior [25,27,31,34]. Fig. (2) shows examples of this pattern for the representative PVH and PIR areas of mice after either $2 \mathrm{~h}$ endotoxin pretreatment to induce sickness behavior or 4 daily 15 min sessions of forced swim stress (RFS), which induces chronic passivity, an animal analogue of depressive passivity [26,35]. The mice in these experiments were challenged with a $1 \mathrm{~h}$ exposure to a fresh cage (endotoxin) or a final 15 min swim one hr prior to anesthesia and perfusion. The "depressive" pattern is much more pronounced after endotoxin, which causes complete behavioral inactivity, than following the milder RFS procedure, which only reduces subsequent swimming, but is still evident after the latter as well. This same pattern is found in animals after other procedures thought to model depressive symptoms including subjection of mice to chronic subordination stress, intraventricular galanin or reserpine treatment [25], and exposure of rats to learned helplessness [31] or forced swimming in the presence of a genetic vulnerability to anxiety [34]. 

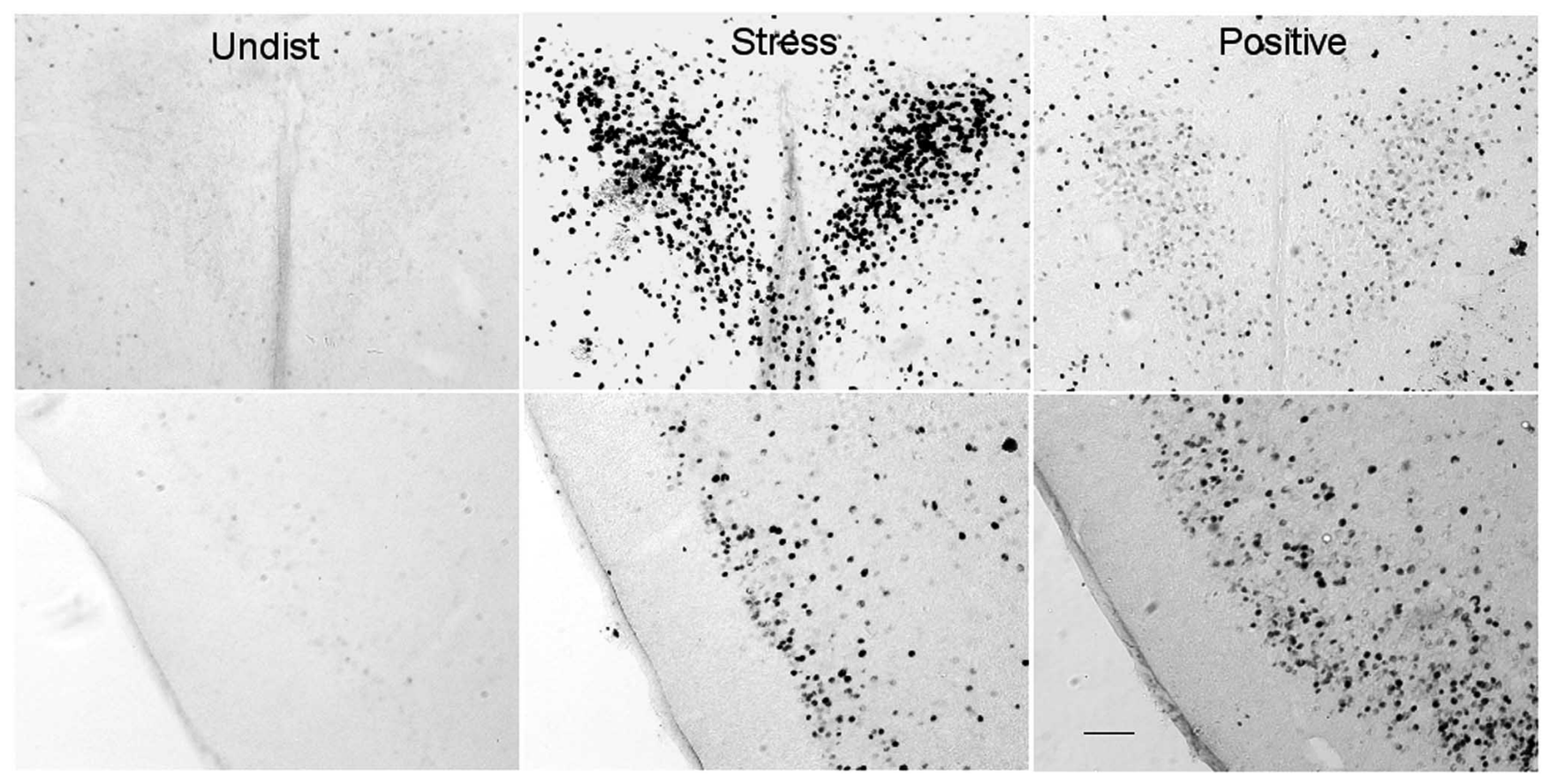

Fig. (1). Evidence for the existence of stress and "active" networks in the mouse brain. The expression of Fos in the PVH (upper panels) and PIR (lower panels) after either $60 \mathrm{~min}$ of restraint stress or $40 \mathrm{~min}$ of operant responding for water reinforcement are shown for representative mice. All animals were anesthetized and perfused at $70 \mathrm{~min}$ after the start of procedures. The stress preferentially activated the $\mathrm{PVH}$ as well as other regions of the stress network while the appetitive task preferentially stimulated the PIR and other "active" areas. Bar represents $100 \mu$. (Stone, E.A and Lin, Y., Unpublished results).

In support of the notion that this neural pattern is both specific to and causative for depressive-like behavior, we have shown that it is reversed for both the stress and "active" networks in the RFS procedure by several divergent classes of antidepressant drugs in temporal correlation with their chronic reversals of immobility (Fig. 3C-E, H-J) [25]. These findings were consistent with a study by Weiss and colleagues showing that local infusion of the $\alpha_{2}$-autoreceptor agonist, clonidine, to inhibit the hyperactive LC of chronically tailshocked rats immediately reversed their increased immobility in the forced swim test [36]. Similarly Marvel et al. [37] and Gaykema and Goehler [27] have demonstrated that infusion of a local anesthetic near hyperactive A2 noradrenergic neurons in the dorsal vagal complex of endotoxin treated rats immediately reverses their behavioral inactivity as well as both the increased Fos responses of their stress regions (PVH, AMYG, BNST) and the reduced responses of their "active" network structures [HIPPO, ventral tegmental area (VTA), dorsal striatum and ventral tuberomammillary nucleus (VTN)]. Similar behavioral effects, though not completely identical neural ones, were obtained by immunotoxic lesion of the A2 neurons prior to endotoxin treatment supporting the hypothesis that the behavioral inactivity caused by the latter is mediated by the hyperactivity of these cells $[38,39]$.

These findings have suggested that it may be possible to control symptoms of depression acutely by selective inhibition of central stress pathways. Our group has confirmed this in mice by showing that 6 -fluoronorepinephine (6FNE), a synthetic catecholamine that is a selective full agonist for $\alpha_{1}$ as well as $\alpha_{2}$-adrenoceptors $[40,41]$, both of which densely populate and inhibit LC, and possibly also A1 and A2 neurons [42-45], produced immediate anti-immobility and anti-anhedonic responses when infused near these brainstem nuclei in mice receiving repeated forced swim, tail suspension or prior endotoxin administration [46]. The inhibitory effect of local 6FNE infusion on the activation of LC neurons during the tail suspension test is shown in Fig. (4). The compound also disinhibited various other types of active motivated behaviors including cage escape, wheel running, and operant responding for water reward [47] (although it did not increase locomotor activity in the open field as discussed below). In the above antidepressant tests, however, the dose-response curves for 6FNE were inverted U-shaped with responses falling off at higher doses. This "therapeutic window" may have resulted from diffusion of higher doses into non-stress brain regions or to the stimulation of additional receptors. With respect to the latter, Doze et al. [48] have shown that different $\alpha_{1}$-receptor subtypes mediate different behavioral functions in rats during stress with the $\alpha_{1 \mathrm{~A}^{-}}$promoting anti-immobility actions and the $\alpha_{1 \mathrm{~B}}$, the reverse during forced swim. It is possible therefore that the pro-immobility $\alpha_{1 B}$-effect predominates at higher doses of 6FNE.

Since 6FNE is polar and incapable of crossing the blood brain barrier (BBB), we synthesized a lipid-soluble pro-drug of it, dipivalyl-6FNE (dp6FNE) (Fig. 5), with the help of the NIMH Chemical Synthesis and Drug Supply Program, and tested this compound systemically in several of the above screens and putative depression models. The addition of pivalyl groups is known to permit catecholamines to penetrate the BBB [49]. It was expected that, once inside the 


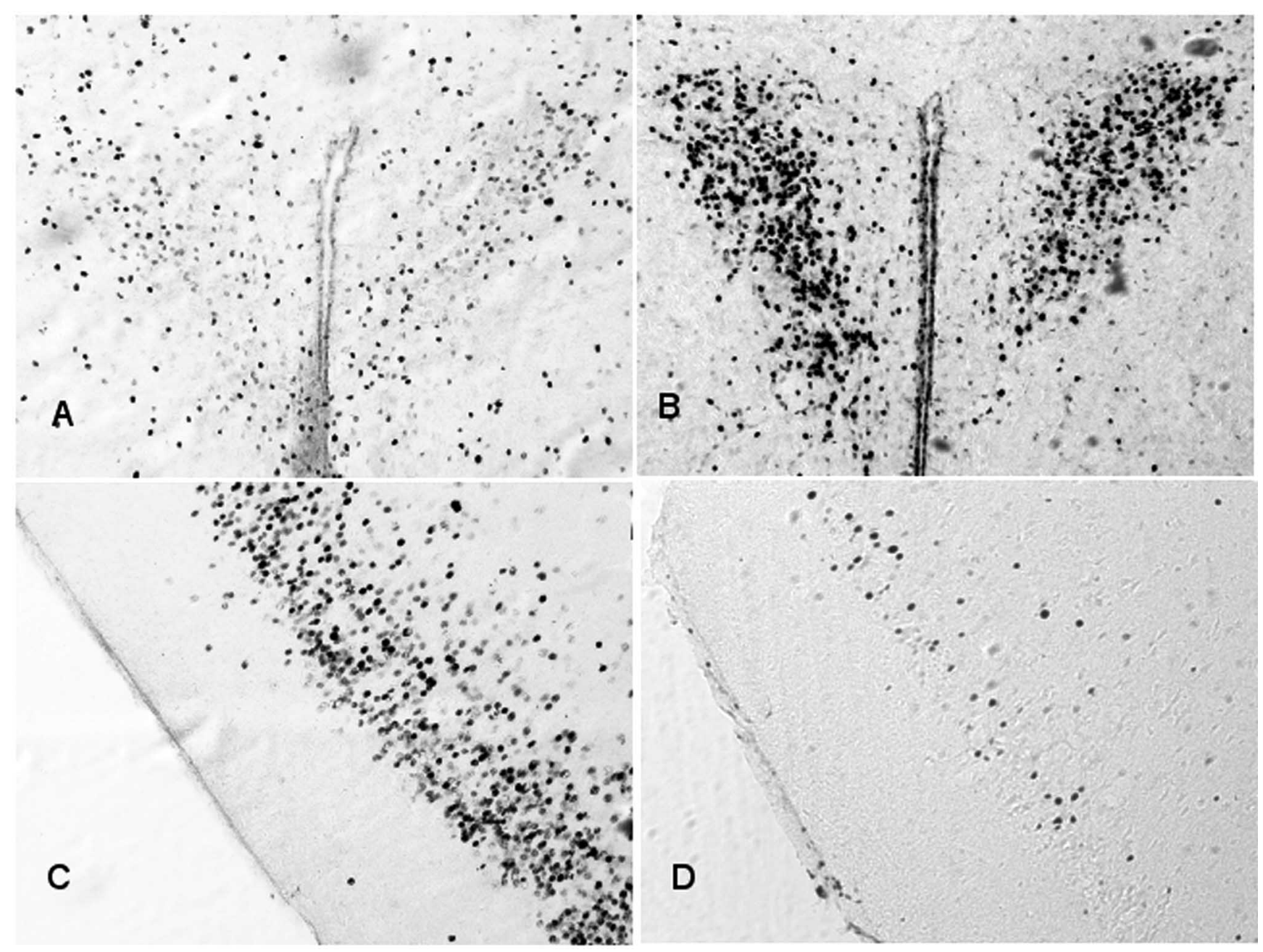

Fig. (2). Sickness behavior due to endotoxin administration is accompanied by marked activation of the stress system along with suppressed function of the "active" network. Mice were injected i.p. with lipopolysaccharide, $100 \mu \mathrm{g} / \mathrm{kg}$, i.p. (B, D), or vehicle $\left(\mathrm{H}_{2} \mathrm{O}\right)(\mathbf{A}, \mathbf{C})$, and were anesthetized and perfused $2 \mathrm{~h}$ later during the period of peak behavioral inactivity. The PVH (upper panel) was markedly activated while the PIR (lower panel) almost completely inhibited (D versus C). Bar represents $100 \mu$. Previously unpublished micrographs from [26].

brain, dp6FNE would be cleaved by tissue esterases to yield free $6 \mathrm{FNE}$ which could then stimulate membranal adrenergic receptors [50]. We further hypothesized that the freed catecholamine would preferentially activate the inhibitory $\alpha_{1}$ - and $\alpha_{2}$-receptors near the LC, A1 and A2, relative to the same receptors in forebrain postsynaptic projection areas since only the former are likely to be highly sensitive autoreceptors [51,52]. The selective stimulation of the brainstem receptors was critical to the targeting strategy since postsynaptic adrenergic receptors in forebrain projection areas, in fact, appear to mediate the proimmobility and pro-anxiety effects of high levels of noradrenergic neurotransmission [53,54]. An additional problem was that dp6FNE will also be taken up and converted to $6 \mathrm{FNE}$ in peripheral tissues, where it will stimulate cardiovascular $\alpha_{1}$-receptors possibly causing adverse clinical effects. We therefore routinely administered a low dose $(0.2 \mathrm{mg} / \mathrm{kg})$ of prazosin, along with the pro-drug, to selectively block peripheral $\alpha_{1}$-receptors. This dose is below that necessary to penetrate the BBB or produce any known behavioral effect in our mice [55].
Preliminary results thus far have been positive and indicate that the pro-drug possesses significant antiimmobility and anti-anhedonic effects in the above screens and models [56]. Moreover, it is active within minutes of i.p. injection in two of the paradigms that respond only to chronic antidepressant treatment - RFS and endotoxinanhedonia $[35,57]$ - suggesting a very rapid onset of activity. Our previous studies with the RFS procedure have failed to show immediate reversal effects of either DMI, fluoxetine, buproprion or even ketamine (at $10 \mathrm{mg} / \mathrm{kg}$ ) in this model [35]. Higher doses of the NMDA antagonist $(50 \mathrm{mg} / \mathrm{kg})$, however, are effective but also produce stereotypy in our animals.

A dose-response analysis of systemic dp6FNE in the above RFS study has shown an inverted "U" curve similar to that obtained with intracerebral injection of the parent catecholamine with the effective dose being the lowest one tested $(0.1 \mathrm{mg} / \mathrm{kg})$ raising the possibility of action at still lower doses. Such high efficacy, if confirmed, would be advantageous in avoiding side effects. We have also made preliminary tests with a commercially available congener of 

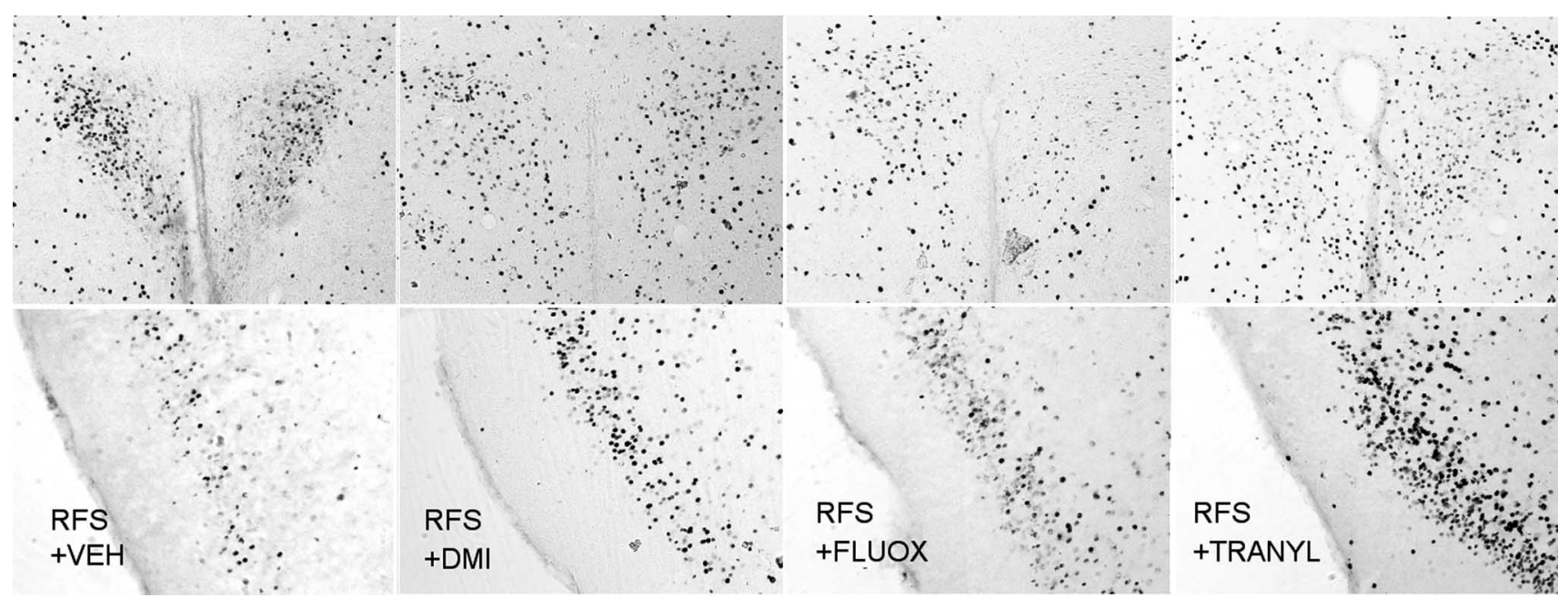

Fig. (3). A mouse model of chronic depression-like passivity, caused by repeated forced swim stress (RFS), activates the stress and inhibits the "active" network, and is reversed by chronic treatment with antidepressants. Mice subjected to RFS for 5 d were given daily administration of vehicle, DMI, fluoxetine (fluox), or tranylcypromine (tranyl) and were processed for Fos immunohistochemistry as above. Each of the antidepressants reduced activation of the PVH and enhanced it in the PIR compared to the veh treatment. Unpublished micrographs from [25].
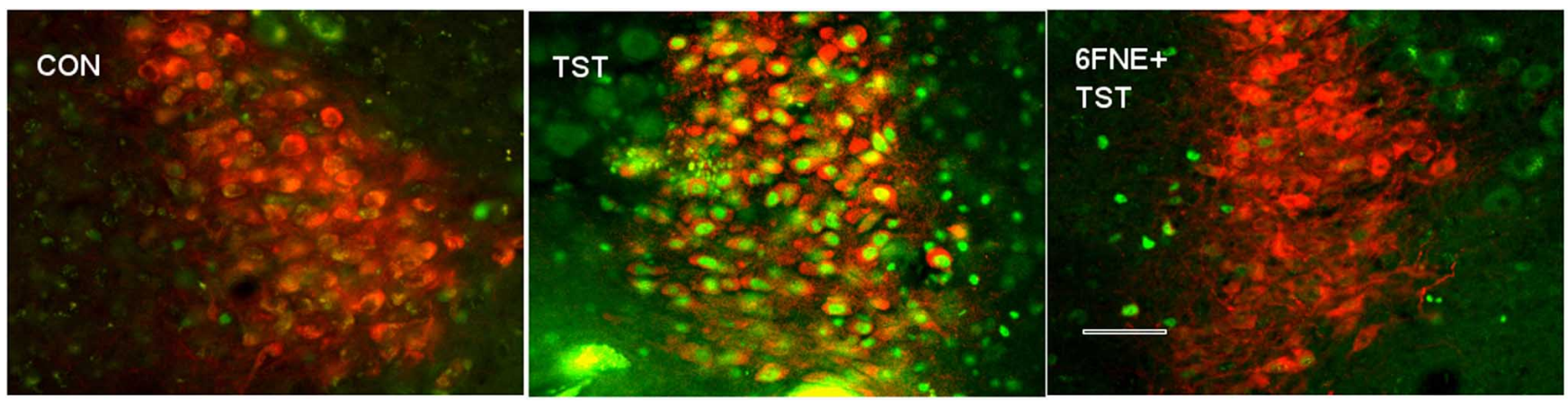

Fig. (4). Inhibition of the LC during tail suspension (TST) by prior infusion of 6FNE in the 4th ventricle. Mice were infused with either vehicle solution (n. saline) (center panel) or 10 nmoles of the catecholamine (right panel) 3 min before being suspended by the tail for 6 min followed $70 \mathrm{~min}$ later by anesthesia and perfusion. Fos and tyrosine hydroxylase (TH) were double immunostained and visualized with alexa fluor-labeled secondary antibodies (green, Fos; red, TH). TST stress resulted in marked expression of Fos throughout the entire LC which was completely blocked by the prior 6FNE infusion. Bar is $50 \mu$. Unpublished micrographs from representative animals in [47].

dp6FNE, dipivalyl-epinephrine (dipivefrin), whose parent catecholamine (epinephrine) is also a full agonist at the above two $\alpha$-receptors [41] and have found it to also have rapid anti-immobility effects in this procedure. We have not tested $\alpha_{1}$-selective adrenergic agonists, such as phenylephrine, since, unlike 6FNE and epinephrine, most of these compounds are known to be partial agonists at brain $\alpha_{1}$-adrenoceptors $[41,58]$ and have much weaker effects in disinhibiting motivated behaviors after intracerebral infusion [59].<smiles>CC(C)(C)C(=O)Oc1cc(F)c(C(O)CN)cc1OC(=O)C(C)(C)C</smiles>

Fig. (5). Chemical structure of dipivalyl-6-fluoronorepinephrine (dp6FNE), synthesized for the project by the NIMH Chemical Synthesis and Drug Supply Program.
It should be emphasized that $6 \mathrm{FNE}$ and its pro-drug have only been tested in animal screens of antidepressant action or putative models of depression. There is still controversy as to the validity of these preclinical tests and their ability to predict clinical efficacy in patients $[60,61]$. However, it should also be noted that there has been good agreement between tests involving very different forms of depressivelike behaviors including passivity, anhedonia and anxiety and that the presumed mechanism of action of these agents as inhibitors of central stress circuit activity is consistent with present notions of the neural basis of depressive behavior.

The rapid actions of dp6FNE and dpEPI in the RFS and endotoxin paradigms coupled with earlier demonstrations of rapid anti-immobility actions of intracerebral clonidine and 6FNE and rapid therapeutic actions of intravenous ketamine in depressed patients [62] argue against the widely held dogma that antidepressant effects require chronic treatment and instead suggest that immediate alleviation of symptoms may be feasible. This concept is also supported by previous 
preclinical demonstrations of rapid anti-learned helplessness actions of intracerebrally administered classical antidepressants [63], and a rapid anti-immobility effect of ivt DMI in the mouse RFS test [46]. As discussed below there is some evidence that chronic stressors that trigger depression retard the uptake of antidepressants by the brain which these intracerebral injections circumvent [46]. This notion is also consistent with reports of a rapid return of depressive symptoms following an abrupt discontinuation of antidepressant treatment $[64,65]$. Taken together these findings suggest that the delayed synaptic or neurogenic changes that result from chronic administration of antidepressants [66] may not be essential for the alleviation of depressive symptoms although they may be required for more persistent functional changes [67]. Brain penetrating pro-drugs that can selectively inhibit central stress circuits may therefore represent a promising addition to a new emerging class of rapidly acting antidepressants.

\section{USEFULNESS IN THE RAPID TREATMENT OF ANXIETY WITH MINIMAL SEDATION}

Although designed primarily for antidepressant action, dp6FNE and its congeners may also be effective in the rapid treatment of anxiety with minimal sedative effects. An anxiolytic effect of 6FNE was observed adventitiously in tests for a possible motor effect of the drug in the open field [42]. Acute ivt infusion in mice that had just been captured from an open field and manually restrained for the injection, was found to reverse the subsequent freezing behavior and avoidance of the central area of the field that is observed when the injected animals are replaced in the field without drug treatment suggestive of an immediate anti-anxiety effect. No reduction in subsequent overall locomotion was observed. This effect was confirmed in the above preliminary studies with dp6FNE, in which a significant dose-dependent increase in center field time accompanied by only a borderline reduction in total locomotion was found after i.p. administration. This action of the prodrug is consistent with its hypothesized selective inhibition of central stress circuits.

\section{FUTURE DIRECTIONS}

\section{Direct Assay of the Selective Inhibitory Targeting of Stress Nuclei}

Thus far the hypothetical selective targeting of stress nuclei with peripheral $\alpha$-agonists has only been suggested from indirect behavioral studies. Future studies are therefore, necessary to test this more directly by assaying neural activation immunohistochemically in various stress and motivational brain regions after systemic administration of a range of doses of the pro-drug before stressful as well as nonstressful conditions.

\section{Avoiding the Stimulation of Cardiovascular $\beta$-Adrenoceptors}

As described above, all previous experiments have included a low-dose of prazosin $(0.2 \mathrm{mg} / \mathrm{kg})$ to block the stimulation of cardiovascular and other peripheral $\alpha_{1}$ receptors by $6 \mathrm{FNE}$ after administration of dp6FNE, However, this may not be necessary if central $\alpha$ - autoreceptors near or on brainstem noradrenergic neurons prove to be more sensitive to the agonist than $\alpha$-receptors on cardiovascular structures. There is some indirect support for this possibility in that the systemic dose of the congener, dipivalyl-norepinephrine (dpNE) that is necessary to significantly raise arterial pressure in dogs $(0.16 \mathrm{mg} / \mathrm{kg})$ appears to be about 10 fold greater than the dose of dp6FNE necessary to reduce immobility in the RFS test in mice $(0.1$ $\mathrm{mg} / \mathrm{kg}$ ), if equivalent doses for the 2 species are computed (mouse dose $=6 \mathrm{X}$ dog dose) $[68,69]$. NE and 6FNE have been shown to have similar affinities for cardiovascular $\alpha$ receptors $[40,69]$.

\section{Potentiating the Efficacy of dp6FNE by Blockade of $\alpha_{1 \mathrm{~B}}-$ Receptors}

As discussed above, $\alpha_{1 \mathrm{~B}}$-receptor activation by catecholamines increases depressive like-behaviors and may interfere with the antidepressant properties of 6FNE [48]. It will therefore be of interest to examine whether coadminstration of dp6FNE with a selective 1B antagonist, such as $(+)$ cyclazosin [70], augments the behavioral effects of the pro-drug and reduces its minimal effective dose or widens its therapeutic range.

\section{Multiple Agonist Cocktails}

The positive results with dp6FNE have encouraged exploration of other autoreceptor agonists to selectively inhibit other types of stress neurons so as to achieve a more complete inhibition of this network. Two such candidates are the glucocorticoid receptors (GR) on medial parvocellular corticotrophin releasing factor ( $\mathrm{CRF}$ )-containing neurons of the PVH and the 5HT1A autoreceptors of serotonergic raphe neurons. GRs are known to potently inhibit CRF -containing neurons controlling the hypothalamic-pituitary-adrenal response to stress [71], long implicated depressive behavioral and neural changes [72]. Two groups have, in fact, reported that low doses of glucocorticoids can produce marked and rapid clinical antidepressant actions [73,74]. With regard to $5 \mathrm{HT} 1 \mathrm{~A}$ autoreceptors, these are known to potently inhibit the functional activity of serotonergic neurons and block the output of this system to several limbic stress areas which have been implicated in chronic poststress anxiety syndromes [75-78]. In exploratory experiments, we have tested a cocktail made up of low doses of three agonists, dp6FNE, corticosterone for GR and 8hydroxy- $N, N$-dipropyl-2-aminotetralin (8OHDPAT) for 5HT1A receptors and have observed a more effective reversal of RFS immobility than with dp6FNE alone as well as one that persists with repeated administration. While combining 3 agonists can produce the multiple drug interactions of polypharmacy, it should be recognized, nonetheless, that the mammalian brain utilizes as many as100 different neurotransmitters each having 5 or more receptors $[79,80]$. Attempting to control a syndrome as complex as depression with only a single drug, therefore, may be overly simplistic and could be one of the reasons why current antidepressants have proven unsatisfactory.

\section{Extension to Stimulants}

Although depressed patients are known to have reduced levels of daily activity that are clearly restored by successful 
antidepressant treatment, stimulants have generally not been found to be effective treatments, even though these drugs can markedly inhibit the activity of the LC [81]. Possible reasons are that these drugs also activate other regions of the stress network, such as the PVH [82], and increase the concentration of $\mathrm{NE}$ at forebrain postsynaptic adrenergic receptors thought to mediate anxiety and passive behaviors. If correct, it might be possible to improve their antidepressant efficacies by combining them with compounds that inhibit stress circuits. This appears to be supported by recent findings of enhanced clinical antidepressant activity resulting from the combined administration of modafinil and fluoxetine, an SSRI with chronic anti-stress actions [83], compared to the effect of the SSRI alone [84].

Following this strategy, we have explored the effects of combinations of modafinil with either dp6FNE or the alpha2 agonist, clonidine, in the treatment of mouse chronic RFSpassivity and endotoxin-sickness models. The results have been encouraging in that dp6FNE appears to potentiate the ability of modafinil to increase active swimming behavior in RFS treated animals while high doses of clonidine appear to dramatically potentiate the reversal of sickness-induced behavioral inactivity by this stimulant. These pilot observations suggest that there are new possibilities involving the use of anti-stress compounds in the presence or absence of stimulants that may lead to new rapid and effective forms of antidepressant treatment.

\section{New Studies with Classical Antidepressants Given Intracerebrally}

As discussed above, previous investigations have shown that classical antidepressant compounds can have rapid and effective antidepressant effects in rodent models of passivity or helplessness behavior [63] when administered intracerebrally rather than systemically $[46,63]$. It has also been found that depressed patients can have reduced concentrations of antidepressants in their brains and that chronic stressors that trigger depressive behaviors in rodents can impair the brain uptake of one of these, DMI, in mice [46]. These findings, which have been largely ignored, raise the possibility that the classical agents may also be capable of selectively inhibiting central stress circuits if present centrally in sufficient concentrations or locations. Future efforts to devise new methods to improve brain penetration and uptake as well as to assess immediate actions of these well tested compounds on the stress and "active" networks are therefore warranted.

\section{Homology of Animal and Human Brain Networks}

It has been demonstrated that the human brain possesses two opposing functional networks, a task-positive (TPN) and a default mode (DMN) circuit [85]. The TPN comprises a group of cortical structures including the intraparietal sulcus, frontal eye field, precentral sulcus, middle temporal region, orbital gyrus, secondary motor area, dorsolateral prefrontal cortex and insula which are active during attentiondemanding cognitive tasks that lead to active coping responses. The DMN, on the other hand, is composed of the posterior cingulate cortex, lateral parietal cortex, medial prefrontal, superior frontal, inferior temporal cortex, parahippocampal gyrus cortex and cerebellar tonsils and shows its greatest activity during mind wandering, negative self evaluation and associated negative emotions [86]. The two networks have reciprocal antagonistic functions such that each is inhibited during conditions that activate the other. The fact that the TPN is involved in cognitive preparations for active coping responses and includes several cortical regions that we have found to be strongly activated during motivated active behaviors, (M2, dorsolateral prefrontal, orbital, temporal and parietal cortex [29]) suggests that the human TPN is homologous to the "active" network of the mouse. The fact that the DMN circuit is suppressed during active attention-demanding cognitive tasks leading to active coping [86], but is highly active during maladaptive negative self evaluations suggests that it may be partly related to the rodent stress network. However, there is still insufficient data on the activity of human stress systems in the brainstem, hypothalamic and subcortex during non-task related activities to clarify the relationship between the DMN and the stress network.

In light of the goal of targeting central stress circuits for selective inhibition by peripheral pharmacological agents, it would be of special interest to determine the effects of dp6FNE and its congeners, with and without stimulants, as well as classical and newer generation antidepressants on the activity of the TPN and DMN networks in primate models. Such an approach could both lead to a more rapid confirmation of the successful targeting of these systems which would facilitate the development of new treatments as well as clarify the evolution and relationship of these circuits across mammalian species.

\section{ACKNOWLEDGEMENTS}

Supported in part by grant 5RO1MH45265. Dr. Chunyang Jin under the direction of Dr. Kenneth Rehder of the NIMH Chemical Synthesis and Drug Supply Program at RTI International carried out the synthesis of dp6FNE for the project.

\section{INSTITUTIONAL APPROVALS}

All of the pilot and published experiments on laboratory mice reported in this paper were approved by the IUCAC of the New York University Langone Medical Center and were conducted in accordance with National Institutes of Health Guide for the Care and Use of Experimental Animals.

\section{CONFLICT OF INTEREST}

None declared.

\section{REFERENCES}

[1] Machado-Vieira R, Salvadore G, Diazgranados N, Zarate CA, Jr. Ketamine and the next generation of antidepressants with a rapid onset of action. Pharmacol Ther 2009; 123: 143-50.

[2] Hashimoto $K$. The role of glutamate on the action of antidepressants. Prog Neuropsychopharmacol Biol Psychiatry 2011; 35(7): 1558-68.

[3] Stone EA, Lin Y, Quartermain D. A final common pathway for depression? Progress toward a general conceptual framework. Neurosci Biobehav Rev 2008; 32: 508-24.

[4] Davidson R. Affective style and affective disorders: perspectives from affective neuroscience. Cogn Emot 1998; 12: 307-30.

[5] Ulrich-Lai YM, Herman JP. Neural regulation of endocrine and autonomic stress responses. Nat Rev Neurosci 2009; 10: 397-409. 
[6] Kvetnansky R, Sabban EL, Palkovits M. Catecholaminergic systems in stress: structural and molecular genetic approaches. Physiol Rev 2009; 89: 535-606.

[7] Davis M, Walker DL, Miles L, Grillon C. Phasic vs sustained fear in rats and humans: role of the extended amygdala in fear $v s$ anxiety. Neuropsychopharmacology 2010; 35: 105-35.

[8] Blair HT, Sotres-Bayon F, Moita MA, LeDoux JE. The lateral amygdala processes the value of conditioned and unconditioned aversive stimuli. Neuroscience 2005; 133: 561-9.

[9] Goddard AW, Ball SG, Martinez J, et al. Current perspectives of the roles of the central norepinephrine system in anxiety and depression. Depress Anxiety 2010; 27: 339-50.

[10] Huber R. Amines and motivated behaviors: a simpler systems approach to complex behavioral phenomena. J Comp Physiol [A] 2005; 191: 231-9.

[11] Kroes RA, Burgdorf J, Otto NJ, Panksepp J, Moskal JR. Social defeat, a paradigm of depression in rats that elicits $22-\mathrm{kHz}$ vocalizations, preferentially activates the cholinergic signaling pathway in the periaqueductal gray. Behav Brain Res 2007; 182: 290-300.

[12] Stone EA, Lin Y, Sarfraz Y, Quartermain D. The role of the central noradrenergic system in behavioral inhibition. Brain Res Rev 2011; 67: 193-208.

[13] Mayberg HS. Defining the neural circuitry of depression: toward a new nosology with therapeutic implications. Biol Psychiatry 2007; 61: 729-30.

[14] Price JL, Drevets WC. Neurocircuitry of mood disorders. Neuropsychopharmacology 2010; 35: 192-216.

[15] Salamone JD. Dopaminergic involvement in activational aspects of motivation: effects of haloperidol on schedule-induced activity, feeding, and foraging in rats. Psychobiology 1988; 16: 196-206.

[16] Swanson L. Cerebral hemisphere regulation of motivated behavior. Brain Res 2000; 886: 113-64.

[17] Kareken DA, Sabri M, Radnovich AJ, et al. Olfactory system activation from sniffing: effects in piriform and orbitofrontal cortex. Neuroimage 2004; 22: 456-65.

[18] Rogers RD, Owen AM, Middleton HC, et al. Choosing between small, likely rewards and large, unlikely rewards activates inferior and orbital prefrontal cortex. J Neurosci 1999; 19: 9029-38.

[19] Baxter MG, Parker A, Lindner CC, Izquierdo AD, Murray EA. Control of response selection by reinforcer value requires interaction of amygdala and orbital prefrontal cortex. J Neurosci 2000; 20: 4311-9.

[20] Hynes CA, Baird AA, Grafton ST. Differential role of the orbital frontal lobe in emotional versus cognitive perspective-taking. Neuropsychologia 2006; 44: 374-83.

[21] Schweimer J, Saft S, Hauber W. Involvement of catecholamine neurotransmission in the rat anterior cingulate in effort-related decision making. Behav Neurosci 2005; 119: 1687-92.

[22] Tabuchi E, Furusawa AA, Hori E, et al. Neural correlates to action and rewards in the rat posterior cingulate cortex. Neuroreport 2005; 16: 949-53.

[23] Salamone JD, Correa M, Mingote S, Weber SM. Nucleus accumbens dopamine and the regulation of effort in food-seeking behavior: Implications for studies of natural motivation, psychiatry, and drug abuse. J Pharmacol Exp Ther 2003; 305: 1-8.

[24] Sheehan TP, Chambers RA, Russell DS. Regulation of affect by the lateral septum: implications for neuropsychiatry. Brain Res Brain Res Rev 2004; 46: 71-117.

[25] Stone EA, Lehmann ML, Lin Y, Quartermain D. Reduced evoked fos expression in activity-related brain regions in animal models of depression. Prog Neuropsychopharmacol Biol Psychiatry 2007; 31 : 1196-207.

[26] Stone EA, Lehmann ML, Lin Y, Quartermain D. Depressive behavior in mice due to immune stimulation is accompanied by reduced neural activity in brain regions involved in positively motivated behavior. Biol Psychiatry 2006; 60: 803-11.

[27] Gaykema RPA, Goehler LE. Ascending caudal medullary catecholamine pathways drive sickness-induced deficits in exploratory behavior: Brain substrates for fatigue? Brain Behav Immun 2011; 25: 443-60.

[28] Davidson RJ. Well-being and affective style: neural substrates and biobehavioural correlates. Philos Trans R Soc Lond Biol Sci 2004; 359: 1395-411.
[29] Stone E, Lin Y, Quartermain D. Activation of central Fos expression by performance of a well learned appetitive operant response (Submitted).

[30] Stone EA, Lin Y, Ahsan M, et al. Role of CNS alpha-1 adrenoceptor activity in central fos responses to novelty. Synapse 2006; 59: 299-307.

[31] Steciuk M, Kram M, Kramer GL, Petty F. Decrease in stressinduced c-Fos-like immunoreactivity in the lateral septal nucleus of learned helpless rats. Brain Res 1999; 822: 256-59.

[32] DellaGioia N, Hannestad J. A critical review of human endotoxin administration as an experimental paradigm of depression. Neurosci Biobehav Rev 2010; 34: 130-43.

[33] Capuron L, Raison CL, Musselman DL, et al. Association of exaggerated HPA axis response to the initial injection of interferonalpha with development of depression during interferon-alpha therapy. Am J Psychiatry 2003; 160: 1342-45.

[34] Muigg P, Hoelzl U, Palfrader K, et al. Altered brain activation pattern associated with drug-induced attenuation of enhanced depression-like behavior in rats bred for high anxiety. Biol Psychiatry 2007; 61: 782-96.

[35] Stone EA, Lin Y. Open-space forced swim model of depression for mice. Curr Protoc Neurosci 2011; Chapter 9: Unit 9.36.

[36] Simson PG, Weiss J, Hoffman LJ, Ambrose MJ. Reversal of behavioral depression by infusion of an alpha-2 adrenergic agonist into the locus coeruleus. Neuropharmacology $1986 ; 25: 385-9$.

[37] Marvel FA, Chen CC, Badr N, Gaykema RP, Goehler LE. Reversible inactivation of the dorsal vagal complex blocks lipopolysaccharide-induced social withdrawal and c-Fos expression in central autonomic nuclei. Brain Behav Immun 2004; 18: 123-34.

[38] Palkovits M, Baffi JS, Pacak K. The role of ascending neuronal pathways in stress-induced release of noradrenaline in the hypothalamic paraventricular nucleus of rats. J Neuroendocrinol 1999; 11: 529-39.

[39] Bienkowski MS, Rinaman L. Noradrenergic inputs to the paraventricular hypothalamus contribute to hypothalamic-pituitaryadrenal axis and central Fos activation in rats after acute systemic endotoxin exposure. Neuroscience 2008; 156: 1093-102.

[40] Daly JW, Padgett W, Nimitkitpaison Y, et al. Fluoronorepinephrines: specific agonists for the activation of alpha and beta adrenergic-sensitive cyclic AMP-generating systems in brain slices. J Pharmacol Exp Ther 1980; 212: 382-9.

[41] Johnson RD, Minneman KP. Characterization of alpha 1adrenoceptors which increase cyclic AMP accumulation in rat cerebral cortex. Eur J Pharmacol 1986; 129: 293-305.

[42] Stone EA, Lin Y, Sarfraz Y, Quartermain D. Antidepressant-like action of intracerebral 6-fluoronorepinephrine, a selective full alpha-adrenoceptor agonist. Int J Neuropsychopharmacol 2011; 14: 319-31.

[43] Stone EA, Lin Y, Sarfraz Y. Activation of central stress systems by

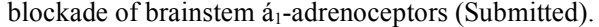

[44] Strazielle C, Lalonde R, Hebert C, Reader TA. Regional brain distribution of noradrenaline uptake sites, and of alpha1-alpha2and beta-adrenergic receptors in PCD mutant mice: a quantitative autoradiographic study. Neuroscience 1999; 94: 287-304.

[45] Jones LS, Gauger LL, Davis JN. Anatomy of brain alpha-1 adrenergic receptors: in vitro autoradiography with [125-I]-heat. J Comp Neurol 1985; 231: 190-208.

[46] Lin Y, Suckow RF, Sarfraz Y, Stone EA. Further evidence for an immediate antidepressant action of intracerebral drug administration in a model of chronic depression. Int $\mathbf{J}$ Neuropsychopharmacol 2011; 14: 691-6.

[47] Stone EA, Lin Y, Sarfraz Y, Quartermain D. Marked behavioral activation from inhibitory stimulation of locus coeruleus $\alpha_{1}$ adrenoceptors by a full agonist. Brain Res 2009; 1291: 21-31.

[48] Doze VA, Handel EM, Jensen KA, et al. alpha(1A)- and alpha(1B)-adrenergic receptors differentially modulate antidepressant-like behavior in the mouse. Brain Res 2009; 1285: 148-57.

[49] Introini-Collison I, Saghafi D, Novack GD, McGaugh JL. Memoryenhancing effects of post-training dipivefrin and epinephrine: involvement of peripheral and central adrenergic receptors. Brain Res 1992; 572: 81-6.

[50] Wei CP, Anderson JA, Leopold I. Ocular absorption and metabolism of topically applied epinephrine and a dipivalyl ester of epinephrine. Invest Ophthalmol Vis Sci 1978; 17: 315-21. 
[51] Raiteri M, Maura G, Versace P. Functional evidence for two stereochemically different alpha-2 adrenoceptors regulating central norepinephrine and serotonin release. J Pharmacol Exp Ther 1983; 224: 679-84.

[52] Adler CH, Meller E, Goldstein M. Receptor reserve at the alpha-2 adrenergic receptor in the rat cerebral cortex. J Pharmacol Exp Ther 1987; 240: 508-15.

[53] Yang X-M, Gorman AL, Dunn AJ. The involvement of central noradrenergic systems and corticotropin-releasing factor in defensive-withdrawal in rats. J Pharmacol Exp Ther 1990; 255: 1064-70.

[54] Weiss JM, Simson PG, Hoffman LJ, et al. Infusion of adrenergic receptor agonists and antagonists into the locus coeruleus and ventricular system of the brain: effects on swim-motivated and spontaneous motor activity. Neuropharmacology 1986; 25: 367-84.

[55] Stone EA, Rosengarten H, Lin Y, Quartermain D. Pharmacological blockade of brain alpha 1-adrenoceptors as measured by ex vivo $\left[{ }^{3} \mathrm{H}\right]$ prazosin binding is correlated with behavioral immobility. Eur J Pharmacol 2001; 420: 97-102

[56] Stone EA, Lin Y, Sarfraz Y, Quartermain D. Rapid antidepressant action of dipivalyl-6-fluoronorepinephrine, a catcholamine prodrug that is brain permeable (Submitted).

[57] Yirmiya R. Endotoxin produces a depressive-like episode in rats. Brain Res 1996; 711: 163-74.

[58] Law-Tho D, Crepel F, Hirsch JC. Noradrenaline decreases transmission of NMDA- and Non-NMDA-receptor mediated monosynaptic EPSPs in rat prefrontal neurons in vitro. Eur $\mathrm{J}$ Neurosci 1993; 5: 1494-500.

[59] Stone EA, Lin Y, Ahsan R, Quartermain D. Role of locus coeruleus $\alpha 1$-adrenoceptors in motor activity in rats. Synapse 2004; 54: 16472.

[60] Dalvi A, Lucki I. Murine models of depression. Psychopharmacology 1999; 147: 14-6.

[61] Bergner CL, Smolinsky AN, Hart PC, et al. Mouse models for studying depression-like states and antidepressant drugs. Methods Mol Biol 2010; 602: 267-82.

[62] Larkin G, Beautrais A. A preliminary naturalistic study of low-dose ketamine for depression and suicide ideation in the emergency department. Int J Neuropsychopharmacol 2011; 14: 1127-31.

[63] Petty F, Sacquitne JL, Sherman AD. Tricyclic antidepressant drug action correlates with its tissue levels in anterior neocortex. Neuropharmacology 1982; 21: 475-7.

[64] Tint A, Haddad PM, Anderson IM. The effect of rate of antidepressant tapering on the incidence of discontinuation symptoms: a randomised study. J Psychopharmacol 2008; 22: 3302.

[65] Haddad PM, Anderson IM. Recognising and managing antidepressant discontinuation symptoms. Adv Psychiatric Treat 2007; 13: 447-57.

[66] Li N, Liu RJ, Dwyer JM, et al. Glutamate N-methyl-D-aspartate receptor antagonists rapidly reverse behavioral and synaptic deficits caused by chronic stress exposure. Biol Psychiatry 2011; 69: 754-61.

[67] Stone EA. Problems with current catecholamine hypotheses of antidepressant drugs. Speculations leading to a new hypothesis. Behav Brain Sci 1983; 6: 535-78.

[68] Travis CC, White RK. Interspecific scaling of toxicity data. Risk Anal 1988; 8: 119-25.

[69] Wang BC, Bloxham DD, Goetz KL. Effect of dipivalyl derivatives of catecholamines on cardiovascular function in the conscious dog. J Pharmacol Exp Ther 1977; 203: 442-8.
[70] Sagratini G, Buccioni M, Gulini U, et al. (+)-Cyclazosin derivatives as $\alpha_{1}$-adrenoceptor antagonists. Med Chem Res 2004; 13: 190-9.

[71] Dallman MF, Akana SF, Jacobson L, et al. Characterization of corticosterone feedback regulation of ACTH secretion. Ann N Y Acad Sci 1987; 512: 402-14.

[72] Doczy EJ, Seroogy K, Harrison CR, Herman JP. Hypothalamopituitary-adrenocortical axis, glucocorticoids, and neurologic disease. Immunol Allergy Clin North Am 2009; 29: 265-84.

[73] DeBattista C, Posener JA, Kalehzan BM, Schatzberg AF. Acute antidepressant effects of intravenous hydrocortisone and CRH in depressed patients: A double-blind, placebo-controlled study. Am J Psychiatry 2000; 157: 1334-37.

[74] Cameron OG, Addy RO, Malitz D. Effects of ACTH and prednisone on mood: incidence and time of onset. Int J Psychiatry Med 1985; 15: 213-23.

[75] Takase LF, Nogueira MI, Bland ST, et al. Effect of number of tailshocks on learned helplessness and activation of serotonergic and noradrenergic neurons in the rat. Behav Brain Res 2005; 162: 299-306.

[76] Grahn RE, Hammack SE, Will MJ, et al. Blockade of alpha1 adrenoreceptors in the dorsal raphe nucleus prevents enhanced conditioned fear and impaired escape performance following uncontrollable stressor exposure in rats. Behav Brain Res 2002; 134: 387-92.

[77] Maswood S, Barter JE, Watkins LR, Maier SF. Exposure to inescapable but not escapable shock increases extracellular levels of 5-HT in the dorsal raphe nucleus of the rat. Brain Res 1998; 783: 115-20.

[78] Graeff FG. On serotonin and experimental anxiety. Psychopharmacology 2002; 163: 467-76.

[79] Haines DE. Fundamental Neuroscience. Philadelphia: Churchill Livingstone Elsevier 2002.

[80] Iversen L. Neurotransmitter transporters and their impact on the development of psychopharmacology. Br J Pharmacol 2006; 147 (Suppl 1): S82-8.

[81] Akaoka H, Roussel B, Lin J-S, Chouvet G, Jouvet M. Effect of modafinil and amphetamine on the rat catecholaminergic neuron activity. Neurosci Lett 1991; 123: 20-2.

[82] Armario A. Activation of the hypothalamic-pituitary-adrenal axis by addictive drugs: different pathways, common outcome. Trends Pharmacol Sci 2010; 31: 318-25.

[83] Musazzi L, Milanese M, Farisello P, et al. Acute stress increases depolarization-evoked glutamate release in the rat prefrontal/frontal cortex: the dampening action of antidepressants. PLoS One 2010; 5: e8566.

[84] Abolfazli R, Hosseini M, Ghanizadeh A, et al. Double-blind randomized parallel-group clinical trial of efficacy of the combination fluoxetine plus modafinil versus fluoxetine plus placebo in the treatment of major depression. Depress Anxiety 2011; 28: 297-302

[85] Fox MD, Snyder AZ, Vincent JL, et al. The human brain is intrinsically organized into dynamic, anticorrelated functional networks. Proc Natl Acad Sci USA 2005; 102: 9673-8.

[86] Hamilton JP, Furman DJ, Chang C, et al. Default-mode and taskpositive network activity in major depressive disorder: implications for adaptive and maladaptive rumination. Biol Psychiatry 2011; 70: 327-33. 